\title{
Commentary
}

\section{U.S.-Guatemala Arbitration Panel Clarifies Effective Enforcement Under Labor Provisions of Free Trade} Agreement

By Tequila J. Brooks, International Employment Policy Specialist, United States \& External Ph.D. Researcher at Tilburg University Law School, Tilburg University, The Netherlands

\section{Introduction}

The first arbitration panel established to determine whether a member state had violated its labor obligations under a free trade agreement found that Guatemala had failed to effectively enforce its labor laws as defined by Chapter 16 of the Dominican Republic-Central America-United States Free Trade Agreement (CAFTA-DR). ${ }^{1}$ The panel also found that the United States did not meet its burden of proving that Guatemala's failure was "in a manner affecting trade between the parties," leading to a conclusion that Guatemala did not in fact fail to conform to its obligations under Article 16.2.1(a) of the CAFTA-DR.

In its report, the arbitration panel provided important guidance on the scope and meaning of "effective enforcement of labor laws," which is the standard set in every U.S. and Canadian free trade agreement since the 1994 North American Free Trade Agreement (NAFTA). ${ }^{2}$ It also clarified the four-pronged analysis required to prove that a member state has violated its labor-related obligations under Article 16.2.1(a). This analysis requires proof of four elements

1 Central America-Dominican Republic-United States Free Trade Agreement (DR-CAFTA), 43 ILM 514 (2004).

2 See, for example, NAALC (North American Agreement on Labor Cooperation), 32 ILM 1499 (1993). 
of the obligation: (1) not to fail to effectively enforce labor laws (2) through a sustained or recurring course of action or inaction (3) in a manner affecting trade between the parties (4) after the date of entry into force of CAFTA-DR. For Guatemala, this date was 1 July $2006 .^{3}$

In determining that Guatemala had failed to effectively enforce its labor laws, the panel encountered evidentiary issues not common to most international trade arbitration proceedings. Much of the evidence submitted by the United States was obtained from the Guatemalan workers and trade union representatives who filed the original petition with the U.s. government. The panel was required to make credibility determinations based on evidence in which witness names were removed to protect them from retaliation by employers and government authorities.

\section{Scope and Meaning of Effective Enforcement of Labor Laws}

The arbitrators concluded that Article 16.2.1(a) requires a party to effectively enforce its labor laws regardless of which organs of the state are responsible for the enforcement. This conclusion was based on three elements. First were definitions that prescribe the characteristics a statute or regulation must have to qualify as a labor law (including enforcement by the executive branch and not excluding administrative and judicial bodies). Second was the context set by Article 16.3.1 requiring member states to ensure that persons with a legally recognized interest under labor laws have access to judicial and administrative tribunals. Third was the object and purpose of CAFTA-DR, which includes a commitment to protect, enhance, and enforce basic worker rights and to strive to ensure that internationally recognized labor rights are legally recognized and protected. ${ }^{4}$

The panel outlined four key hallmarks of effective enforcement under Article 16.2.1(a). First, effective enforcement is synonymous with the production of results - a change in employer behavior. Second, effective enforcement requires authorities to take appropriate action if they find an employer to be out of compliance with its labor obligations. Third, authorities must detect and remedy noncompliance enough to guarantee that employers comply and

3 Panel Report, In the Matter of Guatemala - Issues Relating to the Obligations Under Article 16.2.1 (a) of the CAFTA-DR (adopted 14 June 2017) [Article 16.2.1(a) Guatemala Panel Report], para. 186 , pp. 6o-61.

4 Ibid., paras. 109-20, pp. 36-39. 
that it can be reasonably expected that other employers will comply as well. ${ }^{5}$ The core of the obligation is that authorities must not be neglectful or unsuccessful in compelling compliance. ${ }^{6}$ The arbitrators specifically rejected Guatemala's argument that intentionality is important to determining effective enforcement. $^{7}$

These principles are best illustrated by the panel's analysis of eight cases in which the United States argued that Guatemala failed to effectively enforce labor laws by not executing judicial compensation and reinstatement orders when employers had unlawfully terminated workers for protected trade unionrelated activities. ${ }^{8}$

The panel found that the evidence supported a conclusion that Guatemalan labor courts failed to effectively enforce the law. The panel's language is unequivocal on this point:

The evidence shows that authorities were unsuccessful in enforcing court orders or neglected their enforcement. Courts specifically and directly responsible for initiating enforcement of and securing compliance with their orders directed reinstatement of groups of employees dismissed for union activity and employers failed or refused to comply with the terms of those orders. They also failed to pay the fines imposed by those courts. The subsequent failure by courts to take effective enforcement action in response signalled to the employers in question that they would not be held accountable for their non-compliance with labor laws. ${ }^{9}$

Delay in enforcement is an important indicator of failure to effectively enforce labor laws. In one case, the panel concluded that Guatemalan labor courts were unsuccessful in enforcing reinstatement orders four years after they had been issued..$^{10}$ In another case, it observed that the time (between one year and five years) that elapsed without enforcement and without justification was long enough to constitute a failure to enforce labor laws."

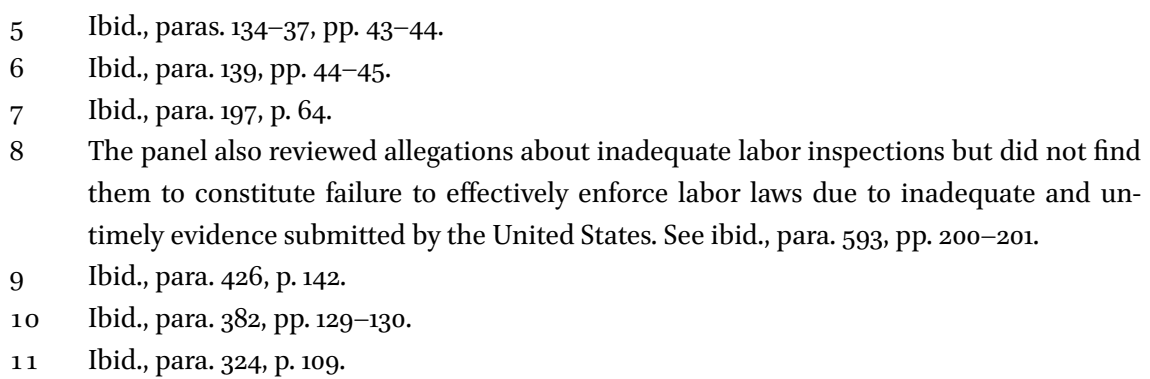




\section{Scope and Meaning of Sustained or Recurring Course of Action or Inaction}

Demonstrating that a member state has failed to effectively enforce its labor laws is only the first step in proving that Article 16.2.1(a) of the CAFTA-DR has been breached. It is also necessary to demonstrate that the failure constituted a "sustained or recurring course of action or inaction." The panel determined that a sustained or recurring course of action or inaction constitutes either (a) repeated and sufficiently similar behavior or (b) prolonged behavior - a connected series of acts or omissions - by a labor law enforcement institution. ${ }^{12}$

The panel identified several factors that could indicate a course of action or inaction. These include evidence of deliberate intention to not enforce laws, bias against types of workers or particular types of labor rights (such as the right to organize trade unions and engage in collective bargaining), and established customs or practices that routinely result in enforcement failures. ${ }^{13}$ Proving each of these factors is not necessary, the panel emphasized-nor is this list of factors exhaustive.

Turning to the eight cases of failure to effectively remedy unlawful termination of employees for protected trade union-related activity, the panel observed that - on each occasion - the enforcement failure was prolonged, from between three and a half months and six years. ${ }^{14}$ The panel observed a pattern of failure to take immediate steps to enforce judicial reinstatement and compensation orders. ${ }^{15}$ The panel, however, did not conduct a full analysis of whether the pattern constituted a sustained or recurring course of action or inaction because it found that this was not the dispositive issue in the case.

\section{The Burden of Establishing that Failure to Enforce Labor Laws is "in a Manner Affecting Trade Between the Parties"}

Key to the panel's interpretation of the clause "in a manner affecting trade between the parties" is whether the action or inaction constituting failure to effectively enforce confers competitive advantage on an employer or employers engaged in trade between the parties. ${ }^{16}$ In adopting this interpretation, the

\footnotetext{
12 Ibid., para. 152, p. 49 .

13 Ibid., para. 437, p. 146.

14 Ibid., para. 431, p. 144.

15 Ibid., para. 440, p. 147.

16 Ibid., para. 190, p. 62.
} 
panel rejected the U.s. argument that the action must have "a bearing on conditions of competition," which the panel found to be too broad..$^{17}$ The panel also rejected Guatemala's argument that a failure to enforce must have the effect of reducing prices, increasing sales volumes, or distorting trade flows-which the panel found to be both fraught with difficulty and impossible to prove. ${ }^{18}$

The panel considered three questions in determining whether Guatemala's failure to effectively enforce labor laws conferred a competitive advantage on the employers in question. First was whether the employers exported to one or more CAFTA-DR member states in a competitive market or competed with imports from another CAFTA-DR party. Second was the effects the failures had on those companies. Third was whether the effects conferred competitive advantage on the companies in question. ${ }^{19}$ In assessing the U.s. argument that the failure to enforce court orders against shipping companies lowered both their costs and those of the Guatemalan exporters that used their services, the panel found that the United States had not submitted enough evidence to make such a conclusion based on the relatively low "balance of probabilities" test. ${ }^{20}$ The evidence required would have been fourfold: one, Guatemalan exporters shipped from Guatemala's main port during relevant times; two, the companies affected by failures in effective enforcement of labor laws were used by exporters; three, the costs of the shipping companies in question were reduced as a result of failure to enforce labor court orders; and, four, the cost savings were passed on to exporters. ${ }^{21}$

\section{Special Evidentiary and Credibility Issues}

Evidentiary issues arose in almost every aspect of the panel's report. Inadequate procedural rules made it difficult for the panel to analyze the sufficiency of the evidence the parties had provided. ${ }^{22}$ After the arbitration hearing, the United States attempted to introduce 2,700 pages of evidence into the record. The panel declined to admit the evidence, finding the submission to be

\footnotetext{
17 Ibid., para. 184, p. 60.

18 Ibid., paras. $178-8$ o, pp. $5{ }^{8-59}$.

19 Ibid., para. 449, pp. 150-51.

20 Ibid., para. 454, p. 152.

21 Ibid.

22 Ibid., para. 232, pp. 77-78.
} 
untimely and observing that the United States provided no justification for not introducing the evidence at the time of its initial written submission. ${ }^{23}$

A number of exhibits submitted by the United States removed identifying information for workers, labor inspectors. and judges in order to protect them from reprisals from their employers and Guatemalan authorities. ${ }^{24}$ After considering Guatemala's arguments, the panel concluded that categorically excluding all exhibits with identifying information removed had no basis. ${ }^{25}$ The panel determined that it would consider such evidence on a case-by-case basis to determine whether its probative value outweighed any prejudicial effects the evidence might have. ${ }^{26}$ Indicia that the panel considered to accord anonymous witness statements reliability included the availability of corroboration with other evidence, verifiability in independent sources, proof that testimony was spontaneous rather than suggested, direct observation by the declarant, and the presence of a solemn oath of truthfulness. ${ }^{27}$

\section{Significance of the Decision}

One critical advancement made by the decision is its acknowledgment of the importance and standing of fundamental labor rights in a free trade context. The decision does not weaken, call into question, or alter fundamental labor rights such as freedom of association and the right to collective bargaining. In fact, the decision contains a number of findings on Guatemala's failure to effectively enforce labor laws based on such painstakingly careful analysis of evidence and assessment of credibility that they likely meet the legal test for res judicatameaning the findings could be relied upon in other legal proceedings.

The main stumbling block in demonstrating a breach of CAFTA-DR Article 16.2.1(a) was not due to a failure to recognize fundamental labor rights, but instead to the difficulty of meeting the rigors of evidentiary standards in an international trade arbitration proceeding. The United States failed to demonstrate a breach of Article 16.2.1(a) because of the difficulty of meeting the rigorous evidentiary standards and the legal standards set in Article 16.2.1(1). Although the standard of demonstrating "in a manner affecting trade between the parties" as established by the Arbitration Panel may not be impossible to meet, it

\footnotetext{
23 Ibid., para. 419, p. 140.

24 Ibid., paras. 238-39, p. 79 .

25 Ibid., para. 245 , pp. $82-83$.

26 Ibid.

27 Ibid., para. 246, p. 83 .
} 
is clearly burdensome. This will be the case for future proceedings under the CAFTA-DR and under the labor provisions of other U.s. free trade agreements with the same legal test. ${ }^{28}$

28 The only exception is the legal test set in the NAALC, which is that failure to effectively enforce a limited number of labor laws must be (a) trade-related and (b) covered by mutually recognized labor laws. NAALC, 32 ILM 1499 (1993), Article 29.1. 